\title{
A Review of the Opioid Epidemic: What Do We Do About It?
}

Edward A. Shipton · Elspeth E. Shipton · Ashleigh J. Shipton

Received: December 22, 2017 / Published online: April 6, 2018

(C) The Author(s) 2018

\section{ABSTRACT}

The opioid epidemic, with its noticeable increase in opioid prescriptions and related misuse, abuse and resultant deaths in the previous 12 years, is a particularly North American phenomenon. Europe, and particularly lowand middle-income countries, appear to be less influenced by this problem. There is undisputable value in using opioids not only in the treatment of acute pain, but in cancer pain as well. However, opioids are progressively being prescribed more and more for chronic noncancer pain, despite inadequate data on their efficacy. In this paper, we describe the current prevalence of opioid misuse in a number of countries and the rationale for the commencement of opioid therapy. The safe initiation and monitoring of opioid therapy as well as the need for concurrent use of interdisciplinary multimodal therapy is discussed. The possible consequences of long-term use and predictors of high opioid use and overdose are presented. In particular, the management of opioid use disorders and the prevention of opioid abuse and

Enhanced digital features To view enhanced digital features for this article, go to https://doi.org/10.6084/ m9.figshare.6061547.

E. A. Shipton $(\varangle)$ · E. E. Shipton · A. J. Shipton Department of Anaesthesia, University of Otago, Christchurch, New Zealand

e-mail: shiptonea@xtra.co.nz dependence in the young, the old and the pregnant are discussed. Measures to prevent overprescribing and to alleviate risk are described, including the tapering of opioids and the use of opioid deterrents. Finally, the paper looks at the future development of pioneering medications and technologies to potentially treat abuse. In those parts of the world with an opioid epidemic, coroners and medical examiners, private and public health agencies, and agencies that enforce the law need to cooperate in an effort to slow down and reverse the indiscriminate use of prescribing opioids in the long-term for chronic non-cancer pain. Ongoing research is needed to create ways to minimise risks of opioid use, and to provide evidence for effective strategies for treating chronic pain.

Keywords: Acquisition; Long-term opioid therapy; Opioid epidemic; Safe initiation; Use and abuse

\section{INTRODUCTION}

Patients should receive appropriate pain treatment based on a careful consideration of the benefits and risks of treatment options. Opioids are essential for the treatment of short-term acute painful episodes. A distinction must be made between acute, chronic non-cancer pain 
(CNCP) and cancer pain as their significance and management vary [1].

CNCP includes any painful ailment that lasts for 3 months (at the least) or more and is not related to malignancy [2]. CNCP is a destructive phenomenon that may have an overwhelming impact physically, psychologically, socially and economically [1]. CNCP remains a foremost public health challenge around the world. Its prevalence in adults ranges between 8 and 50\% depending on the methods and definitions used and populations studied [2-4]. For example, between a third and a half of the population of the UK are affected by chronic pain [5]. Large numbers of patients with CNCP in nations such as the USA, Australia and Canada are exposed to long-term opioid therapy (LtOT), as described by daily (or near-daily) opioid use for 90 days or more [6].

The opioid epidemic in the USA is characterised by aggressive prescribing practices of medical practitioners, widespread opioid misuse, and increasing rates of prescription and illicit opioid overdose-related deaths [7]. It has become clear that aggressive opioid prescription practices play the biggest role in this phenomenon and contribute to an epidemic of abuse of opioid prescriptions [8]. However, the growth of opioid prescriptions differs noticeably amongst countries [9]. The opioid epidemic, with its noticeable rise of opioid prescriptions, and related misuse and abuse in the past 12 years, has been highlighted as a particular phenomenon in North America and Australia [9]. European countries including Germany and the UK appear to be less affected [10].

In this paper, we describe the prevalence of opioid misuse in a number of countries and the rationale for the initiation of opioid therapy. The safe initiation and monitoring of opioid therapy is discussed, as well as the need for concurrent use of interdisciplinary multimodal therapy.

The possible consequences of long-term opioid use and predictors of high opioid use and overdose are presented. In particular, the management of opioid use disorders and the prevention of opioid abuse and dependence in the young, the old and the pregnant are discussed. Measures to prevent overprescribing and alleviate risk are described, including the tapering of opioids and the use of opioid deterrents. Finally, the paper looks at the future development of pioneering medications and technologies to potentially treat abuse. This article is based on previously conducted studies and does not contain any studies with human participants or animals performed by any of the authors.

\section{PREVALENCE OF OPIOID MISUSE}

\section{USA}

The public health threat involves not only prescription opioid analgesics, but also non-prescription substances such as illicit fentanyl and heroin (available online and on the street) which is also contributing to the current growth in morbidity and mortality associated with opioids [11] Mortality rates due to heroin overdose in the USA have more than trebled from 2010 to 2014 [12]. In 2014 in the USA, drug overdoses exceeded automobile accidents for the first time as the chief cause of accidental death [2]. A rapid increase in the prescription of opioids has been connected to the growth in opioid overdose, with the opioid epidemic possibly contributing to the drop in average life expectancy that has occurred in the USA [13]. In 2015 , more than 33,000 opioid overdose deaths occurred in the USA [14], where the use of opioids (licit and illicit) has risen 10-14 times in the last 20 years [15]. The opioid epidemic was initally the result of the growth in prescription opioid medications, but now includes potent heroin and illicit fentanyl. However, decreasing the supply of prescription opioids should bring this rise down. In the USA, 91 people die on a daily basis from an overdose of opioids [16], approximately $50 \%$ of which are not a result of an opioid product from a prescription [16]. The economic liability of opioid misuse has been projected to be more than $\$ 78$ billion a year in the USA [17]. This does not include the cost to humanity of decreased quality of life, disordered family relationships, psychological distress, and social dysfunction [18]. 
In response to the opioid epidemic, the United States Center of Diseases Control (CDC) created a guideline for opioid prescribing in patients with chronic non-cancer pain (CNCP) [19]. The guideline focuses on the following: when to commence or continue with opioids for chronic pain; the selection of opioids, opioid dosage, duration, follow-up, and termination, and; evaluating risk and attending to harms of opioid use.

\section{Canada}

With the use of defined daily doses, Canada has been found to have the world's second highest rate of opioid prescribing. When the amounts of morphine equivalents dispensed are considered, it obtained the highest rate overall [20]. In Canada, since 2000, the dispensing of opioid prescriptions has grown progressively, from 10,209 defined daily doses per million population per day in 2001-2003, up to 30,540 in 2012-2014 [21, 22]. Canada has created a guideline for opioid therapy in CNCP [22].

\section{Australia}

Opioid sales have increased in Australia, although their population-adjusted use is only a quarter to a third of that in the USA [23]. Trends in opioid utilisation in Australia from 2006 to 2015 have recently been published [24]. The number dispensed, the defined daily doses (DDDs), or oral morphine equivalents (OMEs) have been combined with a measure of the number of persons dispensed opioids, in order to gain insights into Australian trends in prescribed opioid use. Total opioid use increased according to all metrics, especially OME/1000 population/day (by 51\%) and dispensings/1000 population (by 44\%) [24]. There was a $238 \%$ increase in persons being dispensed only strong opioids. The use of strong opioids increased according to dispensings/1000 population (by $140 \%$ ), OME/1000 population/day (by 80\%), and DDD/1000 pop/day (by 71\%) [24]. Weaker opioid use remained stable or declined, and the rate of persons accessing weaker opioids decreased by $31 \%$ [24]. In response, the Faculty of Pain Medicine of the Australian and New Zealand College of Anaesthetists has published a position statement describing the appropriate use of opioids in CNCP [25].

Ironically, the opioid crisis in North America and to a lesser extent in Australia is occurring when approximately two thirds of nations cannot access opioid analgesics, resulting in the ineffective treatment of moderate to severe pain [26].

\section{Germany}

Random samples obtained from a regional German compulsory health insurance company from 2000 to 2010 demonstrated a rising number of opioid prescriptions from $3.31 \%$ to $4.53 \%$ [27]. The prevalence was less when compared to another study (in 2006: 5.7\%; in 2009: 5.9\%), as the use of codeine was excluded in their survey [28]. In the period 2006 to 2010, fentanyl patches were the most frequently prescribed strong opioid in Germany [28].

A German medical guideline for the longterm use of opioids in the treatment of nontumour pain (LONTS) was published in 2009 [29]. Regular updates of the LONTS began in November 2013 [30]. Contraindications to opioids were listed as primary headaches, as well as functional somatic syndromes and mental disorders in which the fundamental symptom was pain [30]. It was felt that opioid therapy should be appraised on an individual basis with consideration of the associated risks (sexual disorders, increased mortality) with long-term therapy [30]. Repeated assessment of efficacy and adverse effects was recommended [30]. It recommended that neither an uncritical growth in opioid application nor the global dismissal of opioid-containing analgesics could be warranted in patients with CNCP [30].

\section{United Kingdom}

A massive growth in strong opioid prescribing has occurred in the UK, with most prescriptions being for CNCP. A cross-sectional study was performed from 2000 to 2010 with the use of the UK Clinical Practice Research Datalink [31]. 
Included in this study were prescriptions of fentanyl, morphine, buprenorphine, and oxycodone given to adult patients. Over the study period, there were $2,672,022$ prescriptions (87.8\% for non-cancer) of strong opioids for 178,692 users $(59.9 \%$ female, $83.9 \%$ non-cancer, mean age $67.1 \pm 17.0$ years) [31]. In the non-cancer group, when compared to the cancer group, the mean annual DDD/1000 inhabitants/day was greater. In a retrospective electronic health care database analysis, with the use of data obtained from the UK Clinical Practice Research Datalink (between January 1, 2008 and December 31, 2012), persons receiving a first opioid prescription were identified [32]. It was found that the prevalence of opioid use disorders over a 5-year period to be 4.61 (95\% CI 4.28-4.96) per 10,000 individuals, or $0.05 \%$. The incidence rate of opioid use disorders was found to be 6.51 (95\% CI 5.93-7.13) patients per 10,000 patient-years exposed [32]. When surveyed by study year, there was no clear indication of a changing trend of opioid use disorders over time [32].

\section{Norway}

In Norway, annual rates of opioid users per 1000 of the population rose from 8.6/1000 in 2005 to $13.3 / 1000$ in 2010 , with the largest increase occurring in the geriatric population [33]. Oxycodone demonstrated the greatest use and increase. Buprenorphine ranked second largest in 2010 at 3.3/1000 persons [33]. The use of morphine remained steady over the years. The mean annual amount in DDDs/person was found to diminish in the youngest age groups between 2005 and 2010, and has begun to show a pattern of declining amounts with rising age as well [33].

\section{New Zealand}

Opioid-related deaths in New Zealand have grown by 33\% from 2001 to 2012 [34]. Deaths most often occurred from methadone, morphine, and codeine (and from oxycodone since its introduction into New Zealand in 2005) as prescribed by healthcare professionals. There was a relatively low use of illicit heroin (due to island isolation) [34]. From 2001 to 2012, there was a constant annual increase in opioid prescriptions in New Zealand. The growth in opioid analgesic deaths was associated with the rise in the numbers of opioid prescriptions [34, 35]. As stated above, the Faculty of Pain Medicine of the Australian and New Zealand College of Anaesthetists has published a position statement describing the appropriate use of opioids in CNCP [25].

\section{ACQUISITION OF OPIOIDS}

In Norway, increasing opioid use coincides with a concentration on pain control. However, it may also be influenced by changing reimbursement policies and the advent of new expedient pharmaceutical formulations [33]. In the future, longitudinal studies accessing various data sources across Europe are necessary to determine the ways that divergent prescribing patterns and health care systems might influence the establishment of opioid use disorders [32].

In the USA, higher opioid use has been driven by the rising use of prescription opioids by the geriatric population (due to the expansion of drug insurance to them), by the growing rates of addiction, by the efforts to counteract the under-treatment of chronic pain, and by the promotion of the use of prescription opioids by industry [36].

In the USA, a 2013 national survey indicated that $74 \%$ of opioid abusers acquired their opioids directly from a single doctor, friend, or relative [37]. In turn, those friends or relatives received their opioids from a clinician [37]. Most opioid abusers' first exposure to opioids began with a lawful prescription for pain [38]. In the USA, up to $40 \%$ of chronic opioid therapy patients may have prescription opioid use disorder [39]. Opioid abuse rises proportionately to the greater use of prescription opioids in controlling pain [40]. Among Medicare beneficiaries, it has been shown that simultaneous prescribing of opioids by numerous providers is common practice [36]. It has been suggested that this is associated with higher rates of hospital admissions related to use [36]. 


\section{RATIONALE FOR THE LONG-TERM USE OF OPIOIDS}

It is a fact that opioids are used for different indications in the USA and in Europe. The German guidelines state that when chronic pain is the main symptom of functional disorders (e.g. fibromyalgia, irritable bowel syndrome) and of mental disorders (e.g. somatoform pain disorder), or when pain is primarily due to headaches, patients should not be treated with opioids $[9,30,41]$. Some American guidelines indicate that opioids are an option for the treatment of fibromyalgia. In the USA and to a lesser extent in Australia, many patients are treated with opioids, without appropriate indications, appropriate precautions, and with excessive doses [10].

Evidence-based research does not support the use of opioids as first-line therapy for patients with CNCP $[10,42]$. Opioids are indicated for active cancer treatment, palliative care and end-of life care where non-opioid treatment has failed [43]. However, opioids are being more and more prescribed for $\mathrm{CNCP}$, despite inadequate data on their efficacy [10]. In addition, opioids are often used as a monotherapy to treat chronic pain [10]. In general, guidelines without a recognized nociceptive or neuropathic cause do not recommend the use of opioids in chronic pain conditions [10].

Opioid analgesics remain a key option in carefully selected patients as a component of multimodal pain management with chronic osteoarthritis pain, with nociceptive or neuropathic low back pain, and with other neuropathic pain states [10]. In summary, opioids should only be prescribed for suitable indications in restricted doses for selected patients and with the provision of advice on their safe use [10]. Non-opioid pharmacotherapy and non-pharmacological therapy should first be optimised [22]. The selection of pharmacotherapy should take into account the chronic pain syndrome, the patient's contraindications, preferences and comorbidities, as well as the risk-benefit profiles of drug-based and nondrug-based treatment replacements [9]. Pharmacotherapy should ideally be combined with physiotherapeutic measures and psychological input as well [41].

\section{THE SAFE INITIATION OF OPIOID THERAPY}

The responsible use of opioids is overriding, and pain control does not supersede safety [8]. Before starting opioids, a comprehensive assessment with documentation should take place. This includes documentation of a comprehensive history, a general medical condition, a psychosocial history that covers psychiatric status, and substance use history [44]. The appropriate physical diagnosis and psychological diagnosis should be established if obtainable prior to starting opioid therapy [25]. Treatment goals that are realistic for pain relief and enhancement in function should first be discussed with all patients [43]. Screening for concurrent benzodiazepine use is essential [8]. If patients are taking benzodiazepines, the prescribing of opioids should be avoided whenever possible [43]. Regarding age, opioid use should be limited in the elderly due to adverse effects (low numbers needed to harm or $\mathrm{NNH}$ ), and restricted in children [25, 45].

\section{Assess Opioid Risk}

Known risks and realistic benefits should first be deliberated. The use of opioid risk assessment tools, such as the Opioid Risk Tool (ORT) and the 'Screener and the Opioid Assessment for Patients with Pain-Revised' (SOAPP-R) is strongly suggested [46]. Written treatment agreements and urine drug testing is reinforced by observational data or expert consensus to mitigate risks [47]. The use of urine screening before starting opioids (and at least annually thereafter) is recommended, as it will detect opioid abusers and decrease opioid abuse $[43,44]$.

\section{Assess Mental Health}

With mental health disorders, opioid analgesics generate an even greater risk for drug overdose 
[48]. Patients with mental health disorders (anxiety or post-traumatic stress disorder, depression, and psychosis) and substance abuse difficulties are more expected to be prescribed chronic opioid therapy (an "adverse selection"), and at greater doses than people without those risk factors [25]. A history of comorbid mental disorders and of sexual or physical abuse, are connected to the persistence of opioid use [49].

\section{What Dose of Opioids Should be Used?}

The US American National Institute of Health guideline has defined the daily morphine equivalent dose per day $(\mathrm{MEQ} / \mathrm{d})$ requiring particular caution as $50 \mathrm{mg} /$ day for general practitioners and $90 \mathrm{mg} /$ day for specialists [19]. In Germany, the MEQ/d requiring attention is $120 \mathrm{mg} /$ day [30] and that for Canada is $90 \mathrm{mg}$ $\mathrm{MEQ} / \mathrm{d}$ [22]. One difference is that immediaterelease opioids tend to be used in the USA whilst extended release opioids tend to be used in Europe [27].

The danger of opioid overdose is increased by 7-9 times when the dose of over $100 \mathrm{mg}$ $\mathrm{MEQ} / \mathrm{d}$ is prescribed [50]. Opioid analgesic deaths are associated with overall excessive doses, especially in opioid-naïve patients, with excessively fast upward titration of opioids, and with inadequate patient monitoring [51].

\section{Use of a Therapeutic Trial and Monitoring}

A short therapeutic trial (up to 12 weeks) should first be considered [41]. Frequent clinical assessments of benefits and harms are needed. Close monitoring of the patients for response and adverse effects in the first weeks of therapy has been recommended [10]. As it is sometimes useful, drug holidays should regularly be discussed with opioid responders [9]. Opioid therapy should not be started without thought of how therapy would be stopped if unsuccessful [43]. If problems occur with opioid tapering, a formal multidisciplinary program should be instituted [22]. Repeated or long-term use of opioids requires periodic reassessments [8]. In Australia, the "5 A's", namely, analgesia, activity, adverse effects, affect and aberrant behaviours, are routinely documented and addressed [25].

\section{Special Considerations in the Young, Old, and Pregnant}

Opioid use becomes problematic in younger patients [52]. An increased probability of opioid overdose, misuse, and addiction occurs in adolescents, yet rarely do they need LtOT [52]. They are best referred to a multidisciplinary pain clinic with an emphasis on improving selfmanagement strategies.

Patients over 65 years of age may have raised susceptibility to opioid accumulation [53]. To decrease the risk of sedation, falls, and overdose in the elderly, lower initial doses, slower titration, the tapering of benzodiazepines, and cautious patient education should be used [52].

In pregnant women on daily opioid therapy, the opioids should be gradually decreased and stopped [52]. If this is not possible, opioids should be counted down to the lowest effective dose. Methadone can be used for opioid-dependent pregnant women [52]. Buprenorphine monotherapy is used in pregnant women as well [54], since naloxone is a danger to the foetus. Opioid therapy whilst pregnant has been associated with poor foetal growth and birth defects, stillbirth, pre-term delivery, and the neonatal opioid withdrawal syndrome [43].

The opioid of choice in lactating mothers is morphine as it gives the least amount of secretion into breast milk compared with other opioids [55]. Both codeine and oxycodone increase the risk for respiratory depression and infant death [8].

\section{CONCURRENT USE OF AN INTERDISCIPLINARY MULTIMODAL PLAN}

Use should be made of non-opioids in the majority of cases of chronic pain [2]. Pharmacotherapy should form part of a multimodal plan that aims to move forward to self-management [25, 43]. Multimodal, opioid-sparing analgesia has been used for more than 20 years. 
Multimodal analgesia combines the use of two or more analgesic agents or techniques that act by different mechanisms [8]. Paracetamol, nonsteroidal anti-inflammatory drugs (NSAIDs), and non-opioid adjuvant analgesic agents (tricyclic antidepressants, anticonvulsants, and noradrenaline serotonin uptake inhibitors) should be considered before opioids $[25,56]$.

Interdisciplinary input providing a combination of non-pharmacological therapies should be used for pain relief. These therapies include pain education, pacing of activity, exercise programs, hot and cold therapies, massage, transcutaneous nerve stimulation, sleep hygiene, and psychological therapies such as cognitive behavioural therapy (to treat comorbid anxiety or depression), and relaxation methods, hypnosis, and music [25, 43, 56]. Recently, a core outcome-domain set to measure the effectiveness of interdisciplinary multimodal pain therapy has been developed [57].

\section{CONSEQUENCES ASSOCIATED WITH LTOT}

A major stumbling block in terms of understanding the consequences of prolonged opioid therapy has been the lack of long-term data for the treatment of non-cancer pain patients. Evidence for LtOT for chronic pain and function (outside of end-of-life care) remains incomplete. Evidence is not sufficient to determine longterm benefits [43]. LtOT should only be instituted in patients who responded to a trial of opioids (opioid responders) [9]. Unfortunately, no study of opioid therapy versus no opioid therapy has been performed that has appraised long-term (>1 year) outcomes connected to pain, quality of life, function, opioid abuse, or addiction [58]. Observational studies submit that risk for serious harm seems to be dose-dependent [50, 58].

Repeated opioid use can result in tolerance through desensitisation of antinociceptive pathways to opioids [59-61]. The use of longterm opioids can give rise to physical dependence that leads to withdrawal symptoms when the medications are suddenly stopped [59]. $\mathrm{M} \mu$ opioid receptors (MOR) in the reward areas of the brain can be activated by opioids. This gives rise to addiction (with intense cravings for opioids) when using increased doses of opioids and for longer periods of time [59]. Opioid-induced hyperalgesia $(\mathrm{OIH})$ is a sensitization of nociceptive pathways by which opioids, paradoxically, cause pain hypersensitivity and increase pain [60-62]. The transmitter and receptor mechanisms of tolerance and OIH are not well understood, but are thought to involve glutaminergic activation via the $N$-methyl- $D$ aspartate (NMDA) receptors [60]. Recent preclinical data have emphasised the role that peripheral MORs play in the formation of $\mathrm{OIH}$ and acute opioid tolerance [63].

Long-term opioid use may create serious risks, such as overdose, fractures, sleep apnoea, myocardial infarction, driving impairment, and markers of sexual and other endocrine dysfunctions $[43,58]$. When compared to urban areas, overdose most likely occurs in people who live in rural areas [64]. In a retrospective study of 2039 patients experiencing an opioid overdose, 78\% were unemployed (78\%) [65].

The CDC requires long-term outcomes of opioid research to be related to pain, quality of life, or function when opioids are matched against placebo or any other treatment [19]. However, no other drug treatment options in CNCP have long-term data [10]. In general, the USA and German systematic reviews diverge in their evaluation of the evidence of the longterm efficacy and safety of LtOT for CNCP, with the Europeans having a more positive view and the Americans a more negative one [30, 66]. However, recent North American and European guidelines now give comparable recommendations for good clinical practice of LtOT for CNCP [9].

\section{PREDICTORS OF HIGH OPIOID USE AND OVERDOSE}

Factors that can predict opioid overdose include the mean daily oral morphine-equivalent dose, pre-existing mental illness, younger age, male sex, pain-related conditions, simultaneous use of benzodiazepines and antidepressants, and substance use disorders (such as alcohol) [67]. 
"Doctor shoppers" as well as patients with multiple comorbid features underwrite most of the fatalities [49].

\section{PREVENTATIVE MEASURES AND RISK MITIGATION}

When patients are at home, all opioids should be stored in a secure place. Lawful supplies of opioids should be restricted by the use of takeback programs that permit people with unused medications to return them for proper disposal [68]. Prescribing practices can be influenced by prescriber education [68]. There should be a single physician prescriber $[52,69]$. Opioid use can be diminished by educating the prescribing physicians to reflect on the contraindications of LtOT, to avoid high-dose opioid therapy, and to access psychosocial services [9]. Prescription drug monitoring programs (PDMPs) should be queried at each prescription refill to facilitate detection of misuse, and considerably improve population surveillance of opioid prescribing and enhance safety [43], and urine drug screens should be routinely utilized when opioids are prescribed beyond the short term [70]. The general public should be educated as well on the risks and benefits of opioid therapy to reduce demand [68]. More research is needed to develop non-addictive replacements to opioids for the treatment of pain [68]. New strategies to reduce harms associated with misuse include making low-cost naloxone more widely available as an antidote for overdose [71]. Thus, opioid risk can be attenuated if opioids are used for the correct indication, under applicable precautions, with the lowest effective dose, and as a part of a multimodal therapy plan [10].

\section{How are Opioids Tapered?}

All guidelines should have criteria for the tapering and stopping of opioids, such as aberrant drug-related behaviours, diversion, unbearable adverse effects, and lack of attaining therapeutic goals [10]. Tapering opioids rather than abrupt cessation is required when weaning from chronic use [70]. However, little evidence exists to guide clinicians in the tapering process and in its risks and benefits [72]. Given the inadequate evidence on the risks of opioid tapering, caution and continuous adherence monitoring are needed [72]. A recent systematic review identified multiple strategies to reduce or discontinue LtOT for chronic pain, such as referring patients to an interdisciplinary, multimodal pain program to support opioid dose reduction [72]. Although some patients reported an improvement in quality of life and function after dose reduction, this was not always the case [53, 72].

Suddenly discontinuing opioids may result in withdrawal symptoms and pain exacerbations [73]. Customizing tapering strategies are therefore needed for slower reduction (10\% per month) or for more rapid reduction [70]. To back up opioid dose decrease, when accessible, patients should be referred to multidisciplinary, multimodal pain programs [72].

\section{Concurrent Drug Misuse and Other Substance Abuse}

Cigarette smokers, those abusing non-opioid illicit drugs, and people with a previous history of being arrested have a higher chance of opioid abuse [74]. There is need for a balance between acceptable access to opioid pain medication for patients, while shielding individuals and society from opioid misuse and abuse [75]. Action is needed to prevent opioid abuse and dependence, and prevent death, in order to enhance treatment capacity in opioid use disorders, and to decrease the supply of illicit opioids, such as illicit fentanyl (that is indistinguishable from prescription fentanyl) [76]. Regular dispensing and monitoring is desired for signs of misuse [52]. Drug misuse is dependent on the number of prescribers, the number of dispensing pharmacies, the use of early refills, and the volume of drugs dispensed [77].

Both opioid agonist and antagonist therapies are used to decrease opioid use and to encourage patients to stay in treatment [78]. Together with psychosocial support, methadone, buprenorphine, and extended-release naltrexone are currently used to attenuate the use of 
illicit opioids, as well as to moderate the risk of relapse and overdoses, while enhancing social function [79]. The buprenorphine/naloxone combination has begun to show significant efficacy and tolerability in multiple populations, such as youths and prescription opioiddependent individuals [54].

\section{Use of Deterrents to Decrease Abuse Potential}

Changing how opioids are formulated, marketed, distributed, and prescribed can decrease the potential for abuse [26]. Other key prevention strategies include avoiding additional sedative hypnotics, prescribing lower doses of opioids, growing availability and accessibility to naloxone, and implementing prescription drug monitoring programs $[25,80]$.

Specific formulations such as tamper-resistant and abuse-deterrent formulations (ADFs) are being designed to resist or deter abuse. ADF opioids have properties that make their abuse more difficult, less attractive, or less rewarding [75]. ADF opioids include technologies designed to impede the roads of abuse expected to be used with that precise opioid [75]. Opioid formulations containing abuse-deterrent properties are more challenging to deploy for snorting or injecting (routes commonly used with misuse due to their rewarding effects) [79]. ADF opioids cannot be entirely abuse proof, because of the need to become bioavailable to provide effective pain relief for patients [75].

Examples of ADF opioids are tablets that resist crushing or dissolving (preventing inhalation, smoking, or injection) or formulations that isolate the opioid in a way that ensures it cannot be removed [26]. Other ADFs contain the combination of the active opioid agent with an antagonist (naltrexone or naloxone), such as buprenorphine with naloxone. If taken correctly, the opioid is effective, but if the drug is meddled with, the antagonist is released and reverses the analgesia [81]. Selective use of ADF opioids may be effective in mitigating opioid abuse and reducing drug diversion [41]. However, their extensive use would be very costly with the unintended consequence of promoting switching to more dangerous opioids such as illicit opioids and heroin [41].

Counselling patients about the dangers of opioid overdose and the use of naloxone is a developing clinical practice that may decrease deaths from overdose $[43,82]$. The evidence seems encouraging for extended-release naltrexone, as it is not prone to misuse or diversion [54].

There are community-based programs that provide education on the prevention of overdose, and distribute naloxone for onlooker administration for patients who consume opioids [82]. The provision of access to medicationassisted treatment (and behavioural therapies) and to syringe service programs (to prevent viral infections from the hepatitis $\mathrm{C}$ virus and human immunodeficiency virus) should be encouraged as well [80].

\section{WHAT OF THE FUTURE?}

New, pioneering medications and technologies are being developed to treat opioid addiction, prevent and reverse overdoses, and diminish mortality [47]. Balancing efficacies at multiple opioid receptors with a single compound is being explored at present. This would result in improved analgesia with reduced side effects [83]. Most progress has been made in the development of $\mathrm{m} \mu$ receptor nociceptin/orphanin FQ peptide receptor $(\mathrm{m} \mu / \mathrm{NOP}$ receptor) bifunctional agonists [83].

The selective 5-HT2C receptor agonist lorcaserin was able to decrease opioid seeking in a rat model [79]. Lofexidine (a $\alpha 2 \mathrm{~A}$ adrenergic receptor agonist) can be used for opioid detoxification as it attenuates withdrawal symptoms (but not the cravings) [79].

The use of $\mathrm{m} \mu$ opioid receptor agonists (such as TRV130) that are not related to rewarding or respiratory effects are being developed [79]. An intranasal naloxone formulation has been devised that provides naloxone levels in blood, corresponding to those attained with parenteral administration [79]. Novel overdose reversal agents need to be created.

Preclinical studies have shown promise for the use of vaccines to create antibodies to 
opioids in the blood to prevent them from entering the brain [79]. Compounds targeting non-opioid pain pathways, such as the endocannabinoid system and dopamine D3 antagonists that are able to decrease morphine tolerance and dependence, are being researched [79].

\section{CONCLUSION}

The International Association for the Study of Pain (IASP) recently issued a position statement on opioids [84]. It states as follows: "Opioids are indispensable for the treatment of severe shortlived pain during acute painful events and at the end of life. Currently no other oral medication offers immediate and effective relief of severe pain" [84].

Opioids are progressively being prescribed for $\mathrm{CNCP}$, despite inadequate data on their efficacy. Predictors of high opioid use and overdose include opioid dose, mental health, and substance abuse. LtOT continues to create serious risks, such as tolerance, physical dependence, addiction, and opioid-induced hyperalgesia.

An opioid risk assessment should be carried out before the initiation of opioid therapy. The use of drug monitoring and the use of non-opioid agents mitigate risk and encourage the safer prescribing of opioids. Strategies are needed that integrate behavioural and physical treatments. Interdisciplinary non-pharmacological therapies should be used as well. Tapering opioids rather than abrupt cessation is required when weaning from chronic use. The young, old, and the pregnant have special needs in the management of opioid use disorders and in the prevention of opioid abuse and dependence.

Various tamper-resistant and ADFs have been designed to resist or deter abuse, but are expensive and may create the use of more dangerous illicit opioids. New, pioneering medications and technologies to treat opioid addiction, to prevent and treat overdoses, and decrease mortality, are being developed.

More appreciation of drivers of prescribing and their adverse results, and more comprehensive research on hospital admissions and deaths that are opioid-related are desirable [56]. The role of drug tampering, drug diversion, and mental and physical comorbidities would need to be considered as well [46]. In those parts of the world with an opioid epidemic, coroners and medical examiners, private and public health agencies, and agencies that enforce the law need to cooperate in an effort to slow down and reverse the opioid epidemic [80]. Ongoing research is needed to create ways to minimise risks of opioid use, and discover other ways that are effective in managing the various types of pain.

\section{ACKNOWLEDGEMENTS}

Funding. No funding or sponsorship was received for this study or the publication of this article.

Authorship. All named authors meet the International Committee of Medical Journal Editors (ICMJE) criteria for authorship for this article, take responsibility for the integrity of the work as a whole, and have given their approval for this version to be published.

Disclosures. Edward A. Shipton, Elspeth E. Shipton, and Ashleigh J. Shipton have nothing to disclose regarding the publication of this paper.

Compliance with Ethics Guidelines. This article is based on previously conducted studies and does not contain any studies with human participants or animals performed by any of the authors.

Data Availability. Data sharing is not applicable to this article as no datasets were generated or analysed during the current study.

Open Access. This article is distributed under the terms of the Creative Commons Attribution-NonCommercial 4.0 International License (http://creativecommons.org/licenses/ by-nc/4.0/), which permits any noncommercial use, distribution, and reproduction in any 
medium, provided you give appropriate credit to the original author(s) and the source, provide a link to the Creative Commons license, and indicate if changes were made.

\section{REFERENCES}

1. Julien N, Lacasse A, Labra O, Asselin H. Review of chronic non-cancer pain research among Aboriginal people in Canada. Int J Qual Health Care. 2018. https://doi.org/10.1093/intqhc/mzx195 (in press).

2. Wilson-Poe AR, Morón JA. The dynamic interaction between pain and opioid misuse. Br J Pharmacol. 2018. https://doi.org/10.1111/bph.13873 (in press).

3. Häuser W, Wolfe F, Henningsen P, Schmutzer G, Brähler E, Hinz A. Untying chronic pain: prevalence and societal burden of chronic pain stages in the general population-a cross-sectional survey. BMC Public Health. 2014;14:352.

4. Andrew R, Derry S, Taylor RS, et al. The costs and consequences of adequately managed chronic noncancer pain and chronic neuropathic pain. Pain Pract. 2014;14:79-94.

5. Fayaz A, Croft P, Langford RM, Donaldson LJ, Jones GT. Prevalence of chronic pain in the UK: a systematic review and meta-analysis of population studies. BMJ Open. 2016;6(6):e010364.

6. Von Korff M, Saunders K, Thomas Ray G, et al. De facto long-term opioid therapy for noncancer pain. Clin J Pain. 2008;24(6):521-7.

7. Clark DJ, Schumacher MA. America's opioid epidemic: supply and demand considerations. Anesth Analg. 2017;125(5):1667-74.

8. Lamvu G, Feranec J, Blanton E. Perioperative pain management: an update for obstetrician-gynecologists. Am J Obstet Gynecol. 2018;218(2):193-9.

9. Häuser W, Petzke F, Radbruch L, Tölle TR. The opioid epidemic and the long-term opioid therapy for chronic noncancer pain revisited: a transatlantic perspective. Pain Manag. 2016;6(3):249-63.

10. Häuser W, Schug S, Furlan AD. The opioid epidemic and national guidelines for opioid therapy for chronic noncancer pain: a perspective from different continents. Pain Rep. 2017;2(3):e599.

11. Pergolizzi JV Jr, LeQuang JA, Taylor R Jr, Raffa RB, NEMA Research Group. Going beyond prescription pain relievers to understand the opioid epidemic: the role of illicit fentanyl, new psychoactive substances, and street heroin. Postgrad Med. 2018;130(1):1-8.

12. Justice USDo. 2016 National drug threat assessment summary Washington (DC): Drug Enforcement Administration; 2016. Available from: https://www. dea.gov/resource-center/2016\%20NDTA\% 20Summary.pdf.

13. Chang KC, Wang JD, Saxon A, Matthews AG, Woody G, Hser YI. Causes of death and expected years of life lost among treated opioid-dependent individuals in the United States and Taiwan. Int J Drug Policy. 2017;43:1-6.

14. Rudd RA, Seth P, David F, Scholl L. Increases in drug and opioid involved overdose deaths-United States, 2010-2015. MMWR Morb Mortal Wkly Rep. 2016;65:1445-52.

15. Manchikanti L, Helm S, Fellows B, Janata JW, Pampati V, Grider JS, Boswell MV. Opioid epidemic in the United States. Pain Physician. 2012;15(3):9-38.

16. Drug overdose deaths in the United States continue to increase in 2015. Atlanta (GA): Centers for Disease Control and Prevention; 2016. Available from: https://www.cdc.gov/drugoverdose/epidemic/ index.html. Accessed December 20, 2017.

17. Florence $\mathrm{CS}$, Zhou $\mathrm{C}$, Luo F, Xu L. The economic burden of prescription opioid overdose, abuse, and dependence in the United States, 2013. Med Care. 2016;54(10):901-6.

18. Manchikanti L, Boswell MV, Hirsch JA. Lessons learned in the abuse of pain-relief medication: a focus on healthcare costs. Expert Rev Neurother. 2013;13(5):527-43.

19. CDC guideline for prescribing opioids for chronic pain-United States, 2016. Available at: https:// www.cdc.gov/mmwr/volumes/65/rr/rr6501e1. Accessed February 16, 2018.

20. Dispensing of prescription opioids in Canada has increased steadily since 2000, from 10,209 defined daily doses per million population per day in 2001-2003 to 30,540 in 2012-2014. International Narcotics Control Board (INCB) Narcotic drugs: estimated world requirements for 2004, statistics for 2002. United Nations Publication Sales. 2004;No.T:.16.XI.2.

21. International Narcotics Control Board (INCB) Narcotic drugs: estimated world requirements for 2016-statistics for 2014. United Nations Publication Sales. 2016;No. T:16.XI.2.

22. Busse JW, Craigie S, Juurlink DN, Buckley DN, Wang L, Couban RJ, Agoritsas T, Akl EA, Carrasco- 
Labra A, Cooper L, Cull C, da Costa BR, Frank JW, Grant G, Iorio A, Persaud N, Stern S, Tugwell P, Vandvik PO, Guyatt GH. Guideline for opioid therapy and chronic noncancer pain. CMAJ. 2017;189(18):E659-66.

23. International Narcotics Control Board (INCB). Report 2016 Narcotic drugs: estimated world requirements for 2017; statistics for 2015. United Nations Publications, New York; 2015. https:// www.incb.org/incb/en/narcotic-drugs/Technical_ Reports/narcotic_drugs_reports.html. Accessed April 12, 2017.

24. Karanges EA, Buckley NA, Brett J, Blanch B, Litchfield M, Degenhardt L, Pearson SA. Trends in opioid utilisation in Australia, 2006-2015: Insights from multiple metrics. Pharmacoepidemiol Drug Saf. 2018. https://doi.org/10.1002/pds.4369 (in press).

25. Faculty of Pain Medicine. Recommendations regarding the use of opioid analgesics in patients with chronic non-cancer pain-position statement. http://fpm.anzca.edu.au/documents/pm1-2010. pdf. Accessed December 20, 2017.

26. Pergolizzi JV Jr, LeQuang JA, Berger GK, Raffa RB. The basic pharmacology of opioids informs the opioid discourse about misuse and abuse: a review. Pain Ther. 2017;6(1):1-16.

27. Schubert I, Ihle P, Sabatowski R. Increase in opiate prescription in Germany between 2000 and 2010: a study based on insurance data. Dtsch Arztebl Int. 2013;110:45-51.

28. Werber A, Marschall U, L'hoest HW, Moradi B, Schiltenwolf M. Opioid therapy in the treatment of chronic pain conditions in Germany. Pain Physician. 2015;18(3):E323-31.

29. Reinecke H, Sorgatz H. S3 guideline LONTS. Longterm administration of opioids for non-tumor pain. Schmerz. 2009;23:440-7.

30. Hauser W, Bock F, Engeser P, et al. Recommendations of the updated LONTS guidelines. Long-term opioid therapy for chronic noncancer pain. Schmerz. 2015;29:109-30.

31. Zin CS, Chen LC, Knaggs RD. Changes in trends and pattern of strong opioid prescribing in primary care. Eur J Pain. 2014;18(9):1343-51.

32. Cooper AJM, Willis J, Fuller J, Benecke H, LeightonScott J, Andersohn F, Kim J, Maier C, Knaggs RD. Prevalence and incidence trends for diagnosed prescription opioid use disorders in the United Kingdom. Pain Ther. 2017;6(1):73-84.

33. Neutel CI, Skurtveit S, Berg C, Sakshaug S. Trends in prescription of strong opioids for 41-80 years old
Norwegians, 2005-2010. Eur J Pain. 2014;18(3):438-46.

34. Shipton EE, Shipton AJ, Williman JA, Shipton EA. Deaths from opioid overdosing: implications of Coroners' inquest reports 2008-2012 and annual rise in opioid prescription rates. Pain Therapy. 2017;6(2):203-15.

35. Häuser $\mathrm{W}$, Schubert $\mathrm{T}$, Scherbaum N, Tölle $\mathrm{T}$. Guideline-recommended vs high-dose long-term opioid therapy for chronic noncancer pain is associated with better health outcomes: data from a representative sample of the German population. Pain. 2018;159(1):85-91.

36. Jena AB, Goldman D, Weaver L, Karaca-Mandic P. Opioid prescribing by multiple providers in Medicare: retrospective observational study of insurance claims. BMJ. 2014;19(348):g1393.

37. Substance Abuse and Mental Health Services Administration. Results from the 2013 National Survey on drug use and health: summary of national findings, NSDUH, MD. Rockville: Substance Abuse and Mental Health Services Administration; 2014.

38. Shah A, Hayes CJ, Martin BC. Characteristics of initial prescription episodes and likelihood of longterm opioid use-United States, 2006-2015. MMWR Morb Mortal Wkly Rep. 2017;66:265-9.

39. Cheatle MD. Prescription opioid misuse, abuse, morbidity, and mortality: balancing effective pain management and safety. Pain Med. 2015;16(Suppl 1):S3-8.

40. Ballantyne JC. Avoiding opioid analgesics for treatment of chronic low back pain. JAMA. 2016;315(22):2459-60.

41. Häuser W, Bock F, Engeser P, Tölle T, WillweberStrumpfe A, Petzke F. Long-term opioid use in noncancer pain. Dtsch Arztebl Int. 2014;111(43):732-40.

42. Els C, Jackson TD, Kunyk D, Lappi VG, Sonnenberg B, Hagtvedt R, Sharma S, Kolahdooz F, Straube S. Adverse events associated with medium- and longterm use of opioids for chronic non-cancer pain: an overview of Cochrane reviews. Cochrane Database Syst Rev. 2017;10:CD012509.

43. Centers for Disease Control and Prevention Public Health Service US Department of Health and Human Services. Guideline for prescribing opioids for chronic pain. J Pain Palliat Care Pharmacother. 2016;30(2):138-40.

44. Manchikanti L, Abdi S, Atluri S, Balog CC, et al. American Society of Interventional Pain Physicians (ASIPP) guidelines for responsible opioid 
prescribing in chronic non-cancer pain: part 2guidance. Pain Physician. 2012;15(3 Suppl):S67-116.

45. Finnerup NB, Attal N, Haroutounian S, McNicol E, et al. Pharmacotherapy for neuropathic pain in adults: a systematic review and meta-analysis. Lancet Neurol. 2015;14(2):162-73.

46. Dale R, Edwards J, Ballantyne J. Opioid risk assessment in palliative medicine. J Community Support Oncol. 2016;14(3):94-100.

47. Nuckols TK, Anderson L, Popescu I, Diamant AL, Doyle B, Di Capua P, Chou R. Opioid prescribing: a systematic review and critical appraisal of guidelines for chronic pain. Ann Intern Med. 2014;160(1):38-47.

48. Ministry of Health New Zealand, available from https://www.health.govt.nz/search/results/opioid. Accessed December 20, 2017.

49. Manchikanti L, Abdi S, Atluri S, Balog CC, Benyamin RM, et al. American Society of Interventional Pain Physicians (ASIPP) guidelines for responsible opioid prescribing in chronic non-cancer pain: part I-evidence assessment American Society of Interventional Pain Physicians. Pain Physician. 2012;15(3 Suppl):1-65.

50. Warner EA. Opioids for the treatment of chronic noncancer pain. Am J Med. 2012;125(12):1155-61.

51. Agarin T, Trescot AM, Agarin A, Lesanics D, Decastro C. Reducing opioid analgesic deaths in America: what health providers can do. Pain Physician. 2015;18(3):E307-22.

52. Kahan M, Wilson L, Mailis-Gagnon A, Srivastava A, National Opioid Use Guideline Group. Canadian guideline for safe and effective use of opioids for chronic noncancer pain: clinical summary for family physicians. Part 2: special populations. Can Fam Physician. 2011;57(11):1269-76.

53. Frank JW, Levy C, Matlock DD, Calcaterra SL, Mueller SR, Koester S, et al. Patients' perspectives on tapering of chronic opioid therapy: a qualitative study. Pain Med. 2016;17:1838-47.

54. Connery HS. Medication-assisted treatment of opioid use disorder: review of the evidence and future directions. Harv Rev Psychiatry. 2015;23(2):63-75.

55. Cobb B, Liu R, Valentine E, Onuoha O. Breastfeeding after anesthesia: a review for anesthesia providers regarding the transfer of medications into breast milk. Transl Perioper Pain Med. 2015;1:1-7.

56. Chou R, Gordon DB, de Leon- Casasola OA, Rosenberg JM, Bickler S, et al. Management of postoperative pain: a clinical practice guideline from the American Pain Society, the American Society of Regional Anesthesia and Pain Medicine, and the American Society of Anesthesiologists' Committee on Regional Anesthesia, executive committee, and administrative council. J Pain. 2016;17:131-57.

57. Kaiser U, Kopkow C, Deckert S, et al. Developing a core outcome-domain set to assessing effectiveness of interdisciplinary multimodal pain therapy: the VAPAIN consensus statement on core outcomedomains. Pain. 2018. https://doi.org/10.1097/j. pain.0000000000001129 (in press).

58. Chou R, Turner JA, Devine EB. The effectiveness and risks of long-term opioid therapy for chronic pain: a systematic review for a National Institutes of Health Pathways to Prevention Workshop. Ann Intern Med. 2015;162(4):276-86.

59. Volkow ND, Koroshetz W. Lack of evidence for benefit from long-term use of opioid analgesics for patients with neuropathy. JAMA Neurol. 2017;74(7):761-2.

60. Lee M, Silverman SM, Hansen H, et al. A comprehensive review of opioid-induced hyperalgesia. Pain Physician. 2011;14(2):145-61.

61. Low Y, Clarke CF, Huh BK. Opioid-induced hyperalgesia: a review of epidemiology, mechanisms and management. Singapore Med J. 2012;53(5):357-60.

62. Rivata C, Ballantyne J. The dark side of opioids in pain management: basic science explains clinical observation. Pain Rep. 2016;570:1-9.

63. Weber L, Yeomans DC, Tzabazis A. Opioid-induced hyperalgesia in clinical anesthesia practice: what has remained from theoretical concepts and experimental studies. Curr Opin Anaesthesiol. 2017;30(4):458-65.

64. Dunn KE, Barrett FS, Yepez-Laubach C, Meyer AC, Hruska BJ, Petrush K, Berman S, Sigmon SC. Opioid overdose experience, risk behaviors, and knowledge in drug users from a rural versus an urban setting. J Subst Abuse Treat. 2016;71:1-7.

65. Boscarino JA, Kirchner HL, Pitcavage JM, Nadipelli VR, Ronquest NA, Fitzpatrick MH, Han JJI. Factors associated with opioid overdose: a 10-year retrospective study of patients in a large integrated health care system. Subst Abuse Rehabil. 2016;7:131-41.

66. Chou R, Deyo R, Devine B et al. The effectiveness and risks of long-term opioid treatment of chronic pain. Evidence report/technology assessment no. 218. (Prepared by the Pacific Northwest Evidencebased Practice Center under contract no. 290-2012- 
00014-I). AHRQ publication no. 14-E005- EF. Rockville, MD: Agency for Healthcare Research and Quality (2014). http://www.effectivehealthcare. ahrq.gov.

67. Peck KR, Ehrentraut JH, Anghelescu DL. Risk factors for opioid misuse in adolescents and young adults with focus on oncology setting. J Opioid Manag. 2016;12(3):2015-6.

68. Pain management and the opioid epidemic: balancing societal and individual benefits and risks of prescription opioid use. Consensus Report, National Academy of Sciences, July 2017.

69. Vissers KCP, Besse K, Hans G, Devulder J, Morlion B. Opioid rotation in the management of chronic pain: where is the evidence. Pain Pract. 2010;10(2):85-93.

70. Dowell D, Haegerich TM, Chou R. CDC guideline for prescribing opioids for chronic pain-United States. MMWR Morb Mortal Wkly. 2016;65:1-49.

71. Bonnie RJ, Kesselheim AS, Clark DJ. Both urgency and balance needed in addressing opioid epidemic: a report from the National Academies of Sciences, Engineering, and Medicine. JAMA. 2017;318(5):423-4.

72. Frank JW, Lovejoy TI, Becker WC, Morasco BJ, Koenig CJ, Hoffecker L, Dischinger HR, Dobscha SK, Krebs EE. Patient outcomes in dose reduction or discontinuation of long-term opioid therapy: a systematic review. Ann Intern Med. 2017;167(3):181-91.

73. Berna C, Kulich RJ, Rathmell JP. Tapering long-term opioid therapy in chronic noncancer pain: evidence and recommendations for everyday practice. Mayo Clin Proc. 2015;90:828-42.

74. Ihongbe TO, Masho SW. Prevalence, correlates and patterns of heroin use among young adults in the United States. Addict Behav. 2016;63:74-81.

75. Webster JR, Markman J, Cone EJ, Niebler G. Current and future development of extended-release, abuse- deterrent opioid formulations in the United States. Postgrad Med. 2017;129(1):102-10.

76. New Zealand Population Statistics. http://www. stats.govt.nz/browse_for_stats/population.aspx. Accessed March 21, $201 \overline{7}$.

77. Blanch B, Buckley NA, Mellish L, Dawson AH, Haber PS, Pearson SA. Harmonizing post-market surveillance of prescription drug misuse: a systematic review of observational studies using routinely collected data (2000-2013). Drug Saf. 2015;38(6):553-604.

78. Modesto-Lowe V, Swiezbin K, Chaplin M, Hoefer G. Use and misuse of opioid agonists in opioid addiction. Cleve Clin J Med. 2017;84(5):377-84.

79. Volkow ND, Collins FS. The role of science in addressing the opioid crisis. $\mathrm{N}$ Engl J Med. 2017;377(4):391-4.

80. Rudd RA, Aleshire N, Zibbell JE, Gladden RM. Increases in drug and opioid overdose deathsUnited States, 2000-2014. MMWR Morb Mortal Wkly. 2016;64(50-55):1378-82.

81. Pergolizzi JV Jr, LeQuang JA. Abuse-deterrent formulations of opioid analgesics. Pain Pract. 2014;14(3):204-6.

82. Mueller SR, Walley AY, Calcaterra SL, Glanz JM, Binswanger IA. A review of opioid overdose prevention and naloxone prescribing: implications for translating community programming into clinical practice. Subst Abus. 2015;36(2):240-53.

83. Günther T, Dasgupta P, Mann A, Miess E, Kliewer A, Fritzwanker S, Steinborn R, Schulz S. Targeting multiple opioid receptors-improved analgesics with reduced side effects. Br J Pharmacol. 2018. https://doi.org/10.1111/bph.13809 (in press).

84. IASP statement on opioids, February 2018. Available at: https://www.iasp-pain.org/Advocacy/ OpioidPositionStatement. Accessed March 10, 2018. 